\title{
LABORATORY EVALUATION OF PHYSICO-CHEMICAL VARIATIONS IN BENTONITE UNDER ELECTROKINETIC ENHANCEMENT
}

\author{
Nasim Mosavat ${ }^{1}$, Erwin $\mathrm{Oh}^{1}$ and Gary Chai ${ }^{3}$ \\ ${ }^{1}$ Griffith School of Engineering, Griffith University, Australia \\ ${ }^{2}$ Centre for Infrastructure Engineering \& Management, Griffith University, Australia
}

\begin{abstract}
When the traditional ground improvement techniques are not practical for a particular situation, alternative technology, such as electrokinetic (EK) soil treatment can be considered. EK treatment method involves applying a low direct current (DC) or a low potential gradient to arrays of electrodes inserted in the low permeable soils simulating migration of electricity, pore water, ions and charged particles across the soil, hence modifying the physicochemical, mechanical and engineering properties of the soil. This study investigates the effects of EK treatment on conductance phenomena and physico-chemical changes of bentonite at different intervals under total applied voltage of $10 \mathrm{~V}$ subjected to specific types of anode enhancement solutions. The cumulative electroosmotic flow and electric current through the sample was measured for 15 days of treatment. The specimens were also tested for moisture content, $\mathrm{pH}$ and undrained shear strength variations over different time periods of 3, 6, 9, 12 and 15 days showing good correlations between the soil parameters.
\end{abstract}

Keywords: Electrokinetic, Enhancement solutions, Bentonite, Physico-chemical

\section{INTRODUCTION}

The use of EK treatment, which is a comparatively new methodology, is being investigated in some parts of the world as a viable in situ soil stabilisation and treatment method [1-10]. EK soil treatment method also termed as electro-chemical soil processing, uses low intensity direct current (DC) or a low electric potential, to remove pore water and modify fine-grained soils, mud, sludge, slurries and sediments by electric potential. The transportation of charged chemical species across the soil involves several complex mechanisms such as electrolysis, electro-osmosis, electromigration and electrophoresis. In this regard, application of direct electric current (EC) has various effects such as:

i. It results in electrolysis of water which brings about oxidation at the anode, generating an acid front, and reduction at the cathode, producing a base front [11]

ii. It generates two migrations: an ionic migration (electromigration) and electrophoresis of colloidal particles.

iii. It establishes an electric potential difference which will lead to generation of electro-osmosis through the sample [12].

This technique can also be enhanced by introducing desirable chemical compounds (enhancement solutions) such as lime, calcium chloride or even tap water to the soil by injecting them at the appropriate electrode, preferably anode. The introduction of an appropriate chemical enhancement solution can be beneficial to decrease the extreme acidity at the anode; manage/neutralise anode $\mathrm{pH}$; facilitate the electro-osmotic flow, and enhance the EK process across the soil. The combined effects of these processes together with various geochemical reactions alter the chemical composition of the soil porous medium and hence modify the physicochemical properties of the soil during the EK treatment.

Although the EK technology has been proven to be useful in many laboratory and field tests, the application of the technology is still limited. This may be due to the complicated and unknown features such as conductance phenomena and electrochemical reactions during this treatment. Field electro-osmotic mechanism is different from laboratory experiment and moreover, the EK treatment with the injection of lime and saline enhancement solutions (chemical stabilisers) has rarely been discussed. In this regard, there a need for a comprehensive experimental program to be carried out for a better fundamental understanding the changes in soil during and after the treatment. Such information would be of particular interest in the improvement of marine soils possessing high moisture content (Mc) and low baring capacity on existing infrastructure. The aim of this study is to evaluate the conductance phenomena and several physico-chemical modifications of bentonite clay subjected to hydrated lime and saline enhancement under the total applied voltage of $10 \mathrm{~V}(0.3 \mathrm{~V} / \mathrm{cm}$ voltage gradient) during 15 days of treatment.

\section{EXPERIMENTAL SOIL}

Some studies have shown that bentonite exhibits much higher buffering capacity (resistance to change in $\mathrm{pH}$ ) because of higher CEC compared with other clay minerals, compared to kaolinite [13]. 
Despite several industrial and engineering applications of bentonite, such deposits exhibit large of swell/shrink behaviour upon moisture fluctuations and being sensitive to the changes in chemical environment. Therefore, it is known as one of the dangerous types of clay and can lead to serious engineering problems such as slope or wall failures, high swell/shrink behaviour leading to differential settlements and large cracks. Therefore, Na-bentonite was selected in this study to investigate the potential of EK treatment technique incorporated with chemical stabilisation to improve/stabilise soft soils. The original properties of the bentonite are summarized in Table 1.

Table 1. Original properties of the bentonite

\begin{tabular}{|c|c|c|}
\hline Soil characteristics & Values & References \\
\hline Clay mineralogy & Bentonite & - \\
\hline Liquid limit (\%) & 650 & AS 1289.3.1.1-1995 \\
\hline $\begin{array}{l}\text { Plasticity index, } \\
(\%)\end{array}$ & 450 & AS 1289.3.1.1-1995 \\
\hline & & AS 1289.3.1.1-1995 \\
\hline $\begin{array}{l}\text { Linear shrinkage, } \\
(\%)\end{array}$ & 27.2 & AS 1289.3.1.1-1995 \\
\hline Activity & 4.9 & $\begin{array}{l}\text { PI/ Percentage of } \\
\text { clay }\end{array}$ \\
\hline Specific gravity, Gs & 2.8 & AS 1289.3.5.1-1995 \\
\hline $\begin{array}{l}\text { Unified soil } \\
\text { Classification }\end{array}$ & $\mathrm{CH}$ & ASTM D 2487-83 \\
\hline $\begin{array}{l}\text { Textural } \\
\text { classification }\end{array}$ & $\begin{array}{l}\text { Heavy } \\
\text { clay }\end{array}$ & $\begin{array}{l}\text { Soil textural triangle } \\
\text { by USDA }{ }^{1}\end{array}$ \\
\hline Colour & Light grey & - \\
\hline Clay (\%) & 92 & AS 1289.3.6.2-1995 \\
\hline Silt (\%) & 6 & AS 1289.3.6.2-1995 \\
\hline Sand (\%) & 2 & AS 1289.3.6.2-1995 \\
\hline $\begin{array}{l}\text { Electrical } \\
\text { conductivity, }(\mu S)\end{array}$ & 397 & AS 1289.4.3.1-1997 \\
\hline $\mathrm{pH}$ & 10 & AS 1289.4.3.1-1997 \\
\hline
\end{tabular}

\section{EXPERIMENTAL MODEL AND SET UP}

The laboratory experiments of EK treatment of soil samples are carried out using the test model developed at the Griffith University. The EK tests are performed in clear glass rectangular tanks of 38 $\mathrm{cm}$ in length and $20 \mathrm{~cm}$ in width, under highly controlled laboratory conditions. A compacted layer of the soil with a thickness of about $17 \mathrm{~cm}$ was placed in the tank to known moisture content value. Tap water having a conductivity of $187 \mu \mathrm{S}$ at $25^{\circ} \mathrm{C}$ was used for the slurry preparation to resemble actual field application. Then, two hollow stainless steel tubes, possessing some drilled holes through their walls, to allow the enhancement liquids to move freely into the sample, were placed $32 \mathrm{~cm}$ apart at the ends of the tank to be served as electrodes. An outlet from cathode chambers is connected to the vacuum pump to facilitate collecting cathode effluent and measuring the cumulative electro-osmotic flow volume. The power distribution cables were attached to the electrodes and connected to the DC power supply, providing total voltage of $10 \mathrm{~V}$. The soils at various normalised distances of $0,0.25,0.5,0.75$ and 1 from the anode, were tested for variations in moisture content (Mc), $\mathrm{pH}$ and undrained shear strength ( $\mathrm{Su}$ ) as a result of EK process for 3, 6, 9, 12 and 15 day periods. The normalised distance is defined as the distance of the testing point from anode, over the total distance between the electrodes. The schematic view of the experimental model has been shown in Fig. 1. In order to aid the EK process, soil samples were subjected to a slow continuous flow of anode enhancement solutions (hydrated lime and saline solution). The saturated hydrated lime in distilled water, had $\mathrm{pH}$ value of 12.4 and electro-conductivity of $8.9 \mathrm{mS}$. Similarly, $0.1 \mathrm{~N}$ calcium chloride was mixed with 1:100 sodium silicate solutions (by the volume of distilled water) and this saline solution was selected as second enhancement liquid during the EK treatment. The $\mathrm{pH}$ of this solution was found to be 9.5 and electro-conductivity value of $15 \mathrm{mS}$. The physico-chemical properties of the hydrated lime (slaked lime), calcium chloride and sodium silicate used in this study are shown in Table 2. The enhancement liquids were permitted through the soil via anode by use of a thin flexible PVC tube connected to an external plastic reservoir, at a small external hydraulic head (with very low discharge of solution, almost dripping). For testing, the upper 20 $\mathrm{mm}$ was first removed to ensure that any surface drying/wetting or disturbance effects were avoided.

\section{METHODOLOGY}

The cathode effluent (liquid) was extracted mechanically via a vacuum pump from the cathode well to measure the accumulated electro-osmotic flow volume for period of 15 days. The electric current between the electrodes was manually monitored using a digital multimeter for everyday. The moisture content (Mc) and $\mathrm{pH}$ variations of the soil samples were evaluated by using the method described in Australian standard AS 1289.2.1.12005 and AS 1289.4.3.1-1997 respectively. The undrained shear strength (Su) of the soil was 
measured directly using a hand vane shear apparatus in accordance with AS 1289.6.2.1-1997.

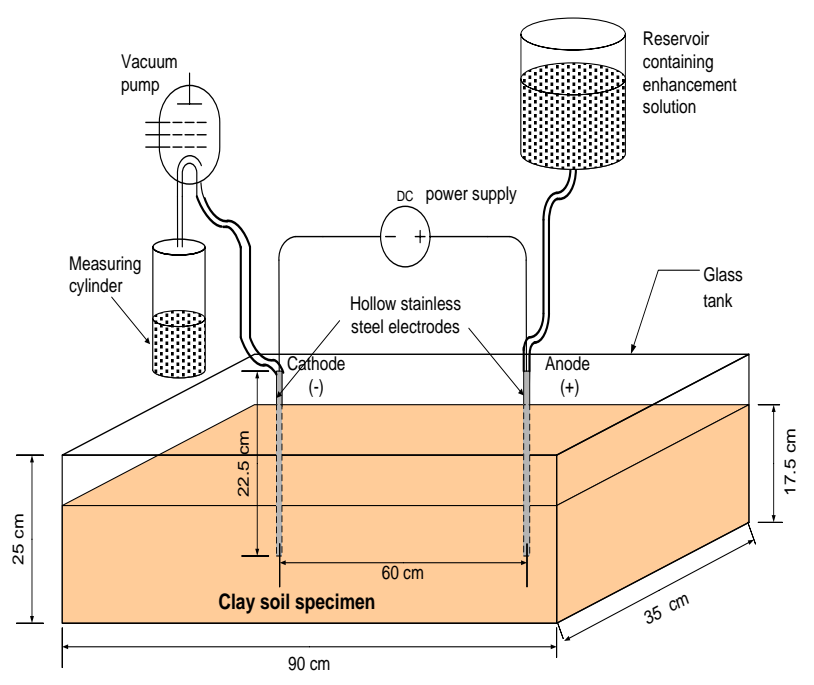

Plan View

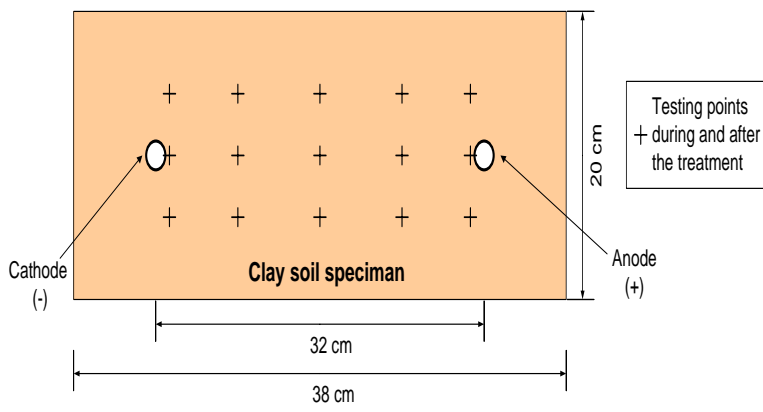

Fig. 1 (a) Schematic view and (b) plan view of the laboratory set up for the EK treatment of the clay soil (not to scale)

Table 2. Properties of the enhancement agents used in this study

\begin{tabular}{|c|c|c|c|}
\hline Properties & $\begin{array}{c}\text { Hydrated } \\
\text { lime }\end{array}$ & $\begin{array}{l}\text { Calcium } \\
\text { chloride }\end{array}$ & \begin{tabular}{|l|}
$\begin{array}{l}\text { Sodium } \\
\text { silicate }\end{array}$ \\
\end{tabular} \\
\hline $\begin{array}{l}\text { Molecular } \\
\text { formula }\end{array}$ & $\mathrm{Ca}(\mathrm{OH})_{2}$ & $\mathrm{CaCl}_{2}$ & $\mathrm{Na}_{2} \mathrm{SiO}_{3}$ \\
\hline $\begin{array}{l}\text { Molar mass } \\
(\mathrm{g} / \mathrm{mol})\end{array}$ & 74.093 & 111 & 122.06 \\
\hline Exact mass & 73.968071 & 110.9848 & \\
\hline Appearance & $\begin{array}{c}\text { Soft white } \\
\text { powder }\end{array}$ & White powder & $\begin{array}{l}\text { Thick } \\
\text { liquid }\end{array}$ \\
\hline Odour & Odourless & Odourless & Odourless \\
\hline Solubility & $\begin{array}{c}\text { Soluble in } \\
\text { glycerol } \\
\text { and acids. } \\
\text { Insoluble } \\
\text { in alcohol. }\end{array}$ & $\begin{array}{c}\text { Soluble in } \\
\text { acetone, acetic } \\
\text { acid }\end{array}$ & $\begin{array}{l}\text { Insoluble } \\
\text { in alcohol }\end{array}$ \\
\hline Toxicity & Low & $\begin{array}{l}\text { Low to } \\
\text { medium } \\
8-9\end{array}$ & Corrosive \\
\hline Acidity & 12.4 & $\begin{array}{c}\text { (anhydrous) } \\
6.5-8.0 \\
\text { (hexahydrate) }\end{array}$ & 11.5 \\
\hline Basicity & 2.37 & - & - \\
\hline
\end{tabular}

\section{RESULTS AND DISCUSSIONS}

\subsection{Conductance Phenomena During EK Process}

Upon the application of DC electric potential through the soil sample across the electrodes, the soil-liquid medium undergoes several complex electrochemical processes that take place within the soil porous media. Some of these processes are initiated immediately after the DC electric potential was applied (e.g. electrolysis of water, electroosmotic flow, current flow, etc), while several other progressions develop with time (e.g. variations in $\mathrm{Mc}, \mathrm{pH}, \mathrm{Su}$, etc). With the increase of treatment durations, some of these modifications (e.g. electroosmotic flow and electric current flow) appear to continue but with a gradually decreasing rate, which is due to the several other system complications developing within the porous media. The most prominent observation of these experiments was the development of wet and drier areas between the electrodes due to positive electro-osmotic flow from anode to cathode.

\subsubsection{Cumulative electro-osmotic flow}

When a electric potential is employed to a claywater structure, electro-osmosis flow occurs from anode to cathode and the mobile DDL moves and drags the solution with it [14]. The variation of total liquid volumes cumulated in the cathode well for bentonite due to electro-osmotic flow subjected to hydrated lime and saline enhancement is presented in Fig. 2. As it can be seen with hydrated lime enhancement higher cumulative electro-osmotic flow volume has been recorded in comparing with saline solution. This can be described by the Helmholtz-Smoluchowsky's (H-S) theory which is the most common theoretical electro-osmotic description and is widely accepted by geotechnical researchers [13, 15]. According to this model the electro-osmosis permeability $\left(\mathrm{k}_{\mathrm{e}}\right)$ under an electrical gradient is indirectly proportional to the viscosity $(\eta)$ of the pore fluid via the following formula:

$\mathrm{k}_{\mathrm{e}}=\frac{\mathrm{D} \zeta}{\eta} \mathrm{n}$

Where $\zeta$ is the zeta potential $(\mathrm{V}), \mathrm{n}$ is the porosity, $\eta$ is the viscosity (FT/L2) and D is the dielectric constant. Saline solution has higher viscosity ( $\eta$ ) compared to hydrated lime due to existence of water-soluble thick liquid; sodium silicate. Therefore, with saline enhancement the viscosity of 
the pore fluid increases and electro-osmotic flow rate decrease. This led to delaying of electroosmotic flow through bentonite and reduction of cumulated cathode effluent.

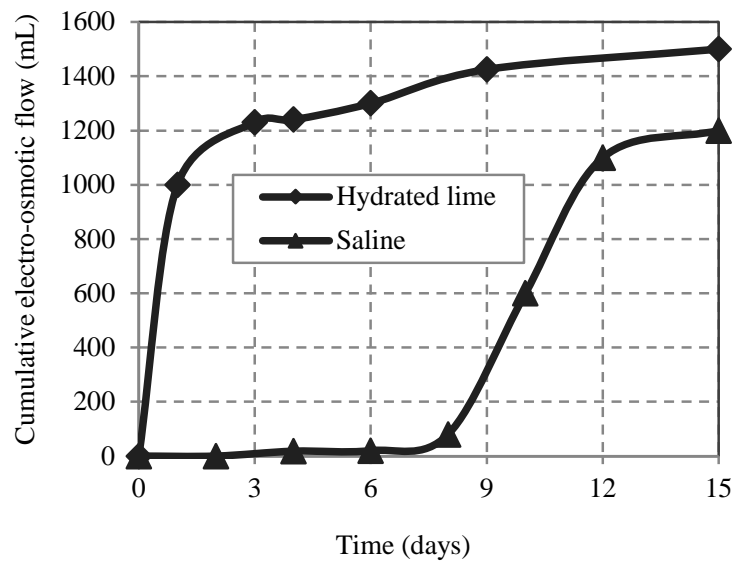

Fig. 2 Variation of cumulative electro-osmotic flow volume with time for bentonite under applied voltage of $10 \mathrm{~V}$ subjected to hydrated lime and saline enhancement solution

\subsubsection{Electric current (EC) flow and electrical resistance $(E R)$}

Fig. 3 represents the variation of electric current flow (EC) and electrical resistance (ER) across bentonite with respect to hydrated lime and saline enhancement solutions. It can be seen that both tests begin with relatively high EC values, while with passing processing time, the current reduces reaching almost constant values. The injection of enhancement solutions through the soil sample would increase the number of cations in the soil pore solution leading to more hydration of cations migrating towards the cathode [16]. According to the Fig 3 higher rate of EC flow was observed with saline enhancement compared to hydrated lime enhancement. This can be due to greater ionic concentration and electro-conductivity of the saline solution, which will increase electrochemical effects (e.g. increase of cation exchange and precipitation on the surface of clay particles) leading to higher initial current through the sample. By dividing the applied voltage by the electric current, the electrical resistance (ER) of bentonite was obtained. The ER of the soil decreased initially and then increased with processing time. This is due to the fact that injection of enhancement solutions would increase the electric current in the sample, which in turn reduces the initial electrical resistance of soil. With increasing treatment time, the electrical resistance increased due to the decline of the electric current through the soil sample.

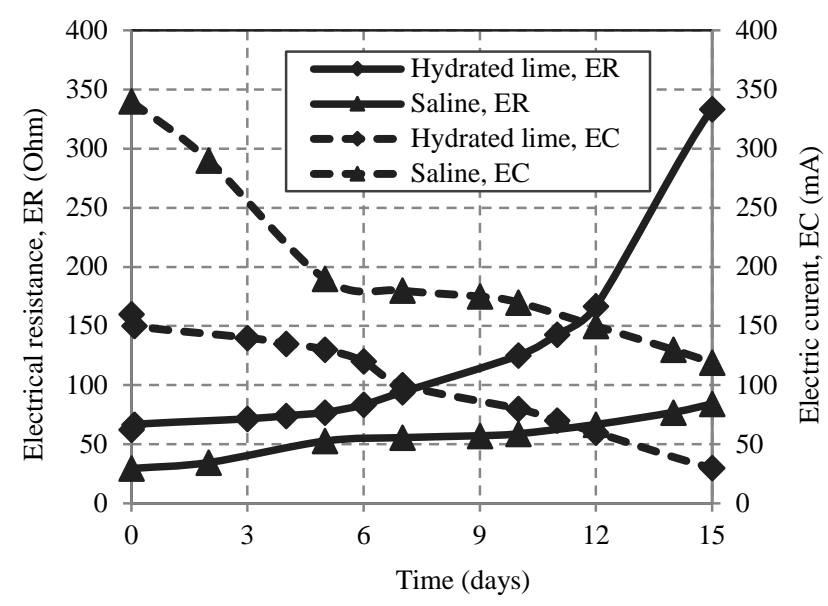

Fig. 3 Variation of electric current flow (EC) and electrical resistance (ER) across bentonite over time under applied voltage of 10 with hydrated lime and saline enhancement

\subsection{EK Effect on Physico-chemical Characteristics of Bentonite Soil}

EK processes can modify the system chemistry of the porous media, hence modifies several physicochemical and engineering properties of the soils.

\subsubsection{EK effect on moisture content (Mc) and undrained shear strength $(\mathrm{Su})$ variations}

The undrained shear strength (Su) and moisture content (Mc) variations of bentonite with time at different normalised distances from anode under 10 $\mathrm{V}$ applied voltage with hydrated lime and saline enhancement are presented in Figs. 4 and 5 respectively. It is noticed that under both EK processing conditions employed, a considerable Mc gradient was built up in the bentonite between the electrodes, forming wet and dry regions. The positive electro-osmotic flow from anode to cathode formed dry regions at the vicinity of the anode and wet areas at the vicinity of the cathode. In this regard, the exact location of wet and dry regions depends on the mineralogical properties of the soil such as permeability characteristics, clay type and content, DDL characteristics, etc [17].

From the Figs. 4 and 5 it can also be observed that there is a considerable $\mathrm{Su}$ gradient in soil sample between the electrodes showing very good correlations with the changes in Mc of the soil across the sample. In general, with increasing 
processing time, the strength appears to increase possessing the highest strength values after 15 days of treatment at 0.25 normalised distance from the anode subjected to both enhancement solutions. Moreover, with saline enhancement, higher degree of shear strength was observed in soil sample compared with hydrated lime enhancement. From these results it can be concluded that the EK treatment with enhancement solutions, has significantly improved soil strength especially at the vicinity of the anode and in the middle of the tank.

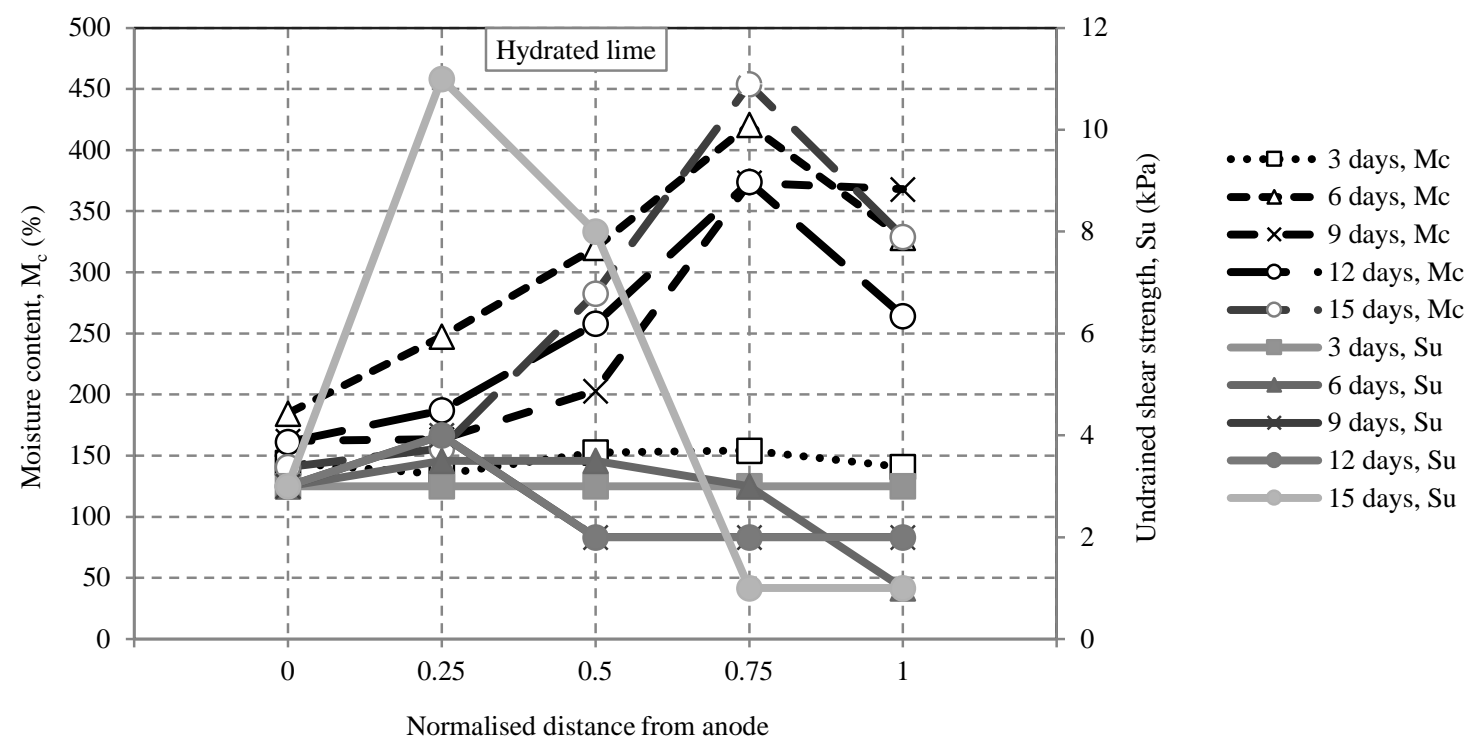

Fig. 4 Shear strength $\left(S_{u}\right)$ and moisture content $\left(M_{c}\right)$ variation of bentonite over time at regular normalised distances from the anode under applied voltage of $10 \mathrm{~V}$ with hydrated lime enhancement

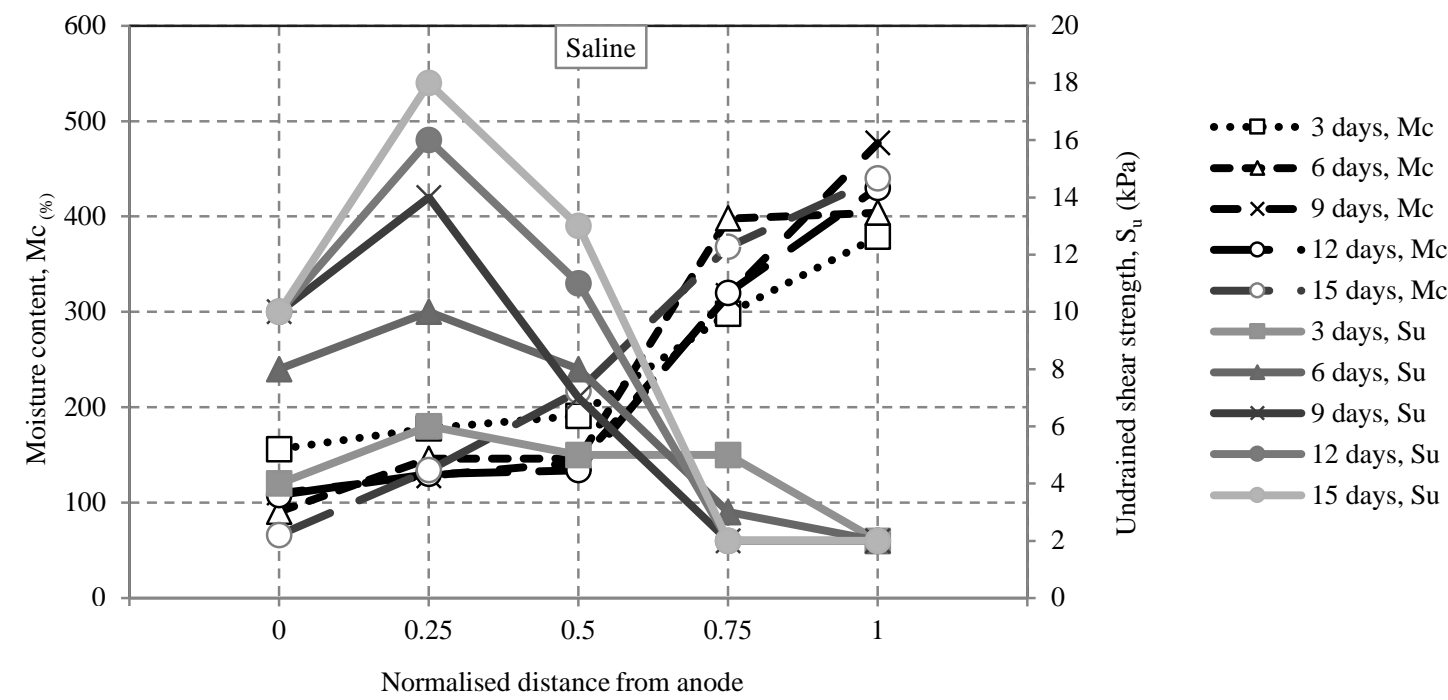

Fig. 5 Shear strength $\left(S_{u}\right)$ and moisture content $\left(M_{c}\right)$ variation of bentonite over time at regular normalised distances from the anode under applied voltage of $10 \mathrm{~V}$ with saline enhancement

\subsubsection{EK effect on $\mathrm{pH}$ variations}

The development of the $\mathrm{pH}$ gradient across the electrodes, for bentonite versus time at regular normalised distances from the anode with hydrated lime and saline enhancement is presented in Figs 6 and 7, respectively. It can be noticed that under the both EK processing conditions, a clear $\mathrm{pH}$ gradient was being developed within the bentonite soil between the electrodes, forming an acid front at the anode and a base front at the cathode. However, the passage of enhancement solutions through the soil 
reduced the extreme acidity near the anode. As it can be observed form Figs. 6 and 7, during the early stages of EK treatment, the $\mathrm{pH}$ of the soil remained unchanged. This is due to the high buffering capacity of bentonite. However with the passage of processing time, the $\mathrm{pH}$ at the vicinity of the anode seems to drop reaching almost lowest $\mathrm{pH}$ value at 15 days of treatment.

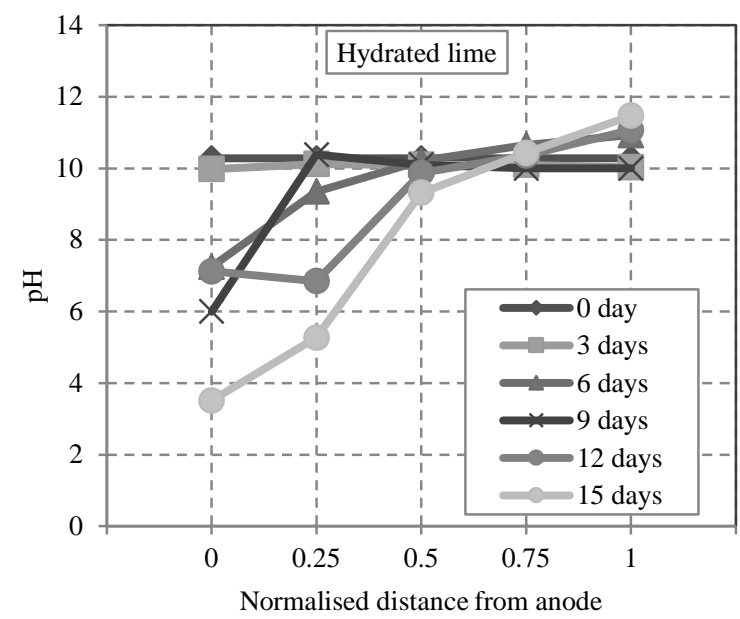

Fig. 6 Variation of $\mathrm{pH}$ of bentonite over time at regular normalised distances from the anode under applied voltage of $10 \mathrm{~V}$ with hydrated lime enhancement

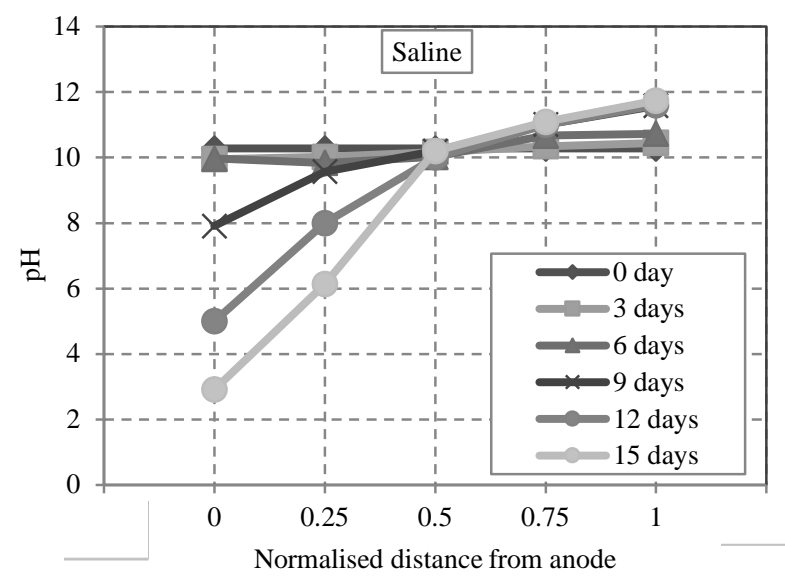

Fig. 7 Variation of $\mathrm{pH}$ of bentonite over time at regular normalised distances from the anode under applied voltage of $10 \mathrm{~V}$ with saline enhancement

\section{CONCLUSIONS}

This paper has presented some laboratory results of a study undertaken to investigate the EK treatment effects in bentonite soil subjected to two enhancement solutions under a predetermined applied voltage gradient of $10 \mathrm{~V}$. From the analysis of the test results the following conclusions can be made:

i. With the application of DC electric potential through the sample, the soil-liquid medium undergoes several physico-chemical and electrical changes due to several complex electrochemical processes which take place within the soil porous media. The most prominent observation of these experiments was the development of wet and dry areas between the electrodes due to positive electroosmotic flow from anode to cathode

ii. Higher rate of electro-osmotic flow is observed during the early stage of the EK process under both processing conditions while with processing time, a gradual decrease in the rate of electro-osmotic flow was noted. With hydrated lime enhancement higher cumulative electro-osmotic flow volume was recorded in comparing with saline enhancement.

iii. The tests began with relatively high currents, however with processing time, the current declined gradually, leading to higher ER values. The electric current through the sample found to be higher with saline enhancement.

iv. Under both EK processing conditions employed in this study, a clear Mc gradient in soil increasing from anode to cathode was built up exhibiting very good correlations with the changes in $\mathrm{Su}$ of the soil. With saline enhancement, higher degree of shear strength was observed in soil sample (at 0.25 normalised distance form the anode) compared with hydrated lime enhancement.

v. Under both EK processing conditions employed, a clear $\mathrm{pH}$ gradient was being developed in the bentonite between the electrodes, creating an acid front at the anode and a base front at the cathode, although the passage of anode enhancement solutions through the soil reduced the extreme acidity near the anode.

\section{REFERENCES}

[1] Acar, Y.B. and A.N. Alshawabkeh, Electrokinetic remediation .1. Pilot-scale tests with lead-spiked kaolinite. Journal of Geotechnical Engineering-Asce, 1996. Vol. 122.(3): pp. 173-185.

[2] Alshawabkeh, A.N. and Y.B. Acar, Electrokinetic Remediation - Pilot-Scale TestResults. Abstracts of Papers of the American Chemical Society, 1994. Vol. 207.(pp. 114ENVR.

[3] Al-Hamdan, A.Z. and K.R. Reddy, Electrokinetic remediation modeling incorporating geochemical effects. Journal of 
Geotechnical and Geoenvironmental Engineering, 2008. Vol. 134.(1): pp. 91-105.

[4] Jayasekera, S., An investigation into modification of the engineering properties of salt affected soils using electrokinetics, University of Ballarat 2008.

[5] Mohamedelhassan, E., Laboratory Model Test on Improving the Properties of Soft Clay by Electrokinetics. 2011.

[6] Schmidt, C.A.B., M.C. Barbosa, and M.S.S. de Almeida, A laboratory feasibility study on electrokinetic injection of nutrients on an organic, tropical, clayey soil. Journal of Hazardous Materials, 2007. Vol. 143.(3): pp. 655-661.

[7] Shang, J.Q. and K.L. Masterson, An electrokinetic testing apparatus for undisturbed/remoulded soils under in-situ stress conditions. Geotechnical testing journal, 2000. Vol. 23.(2): pp. 215-224.

[8] Tjandra, D. and P.S. Wulandari, Improving marine clays with electrokinetics method. Civil Engineering Dimension, 2007. Vol. 9.(2): pp. 98-102.

[9] Turer, D. and A. Genc, Strengthening of soft clay with electrokinetic stabilization method, in 6th symposium on electrokinetic remediation (EREM 2007), C.C. Fernández, M.A.S. Braga, and M.M.P. Currás, Editors.: Spain 2007, pp. 8384.

[10] Yeung, A.T., T.B. Scott, S. Gopinath, R.M. Menon, and C. Hsu, Design, Fabrication, and Assembly of an Apparatus for Electrokinetic Remediation Studies. Geotechnical Testing Journal, GTJODJ, 1997. Vol. 20.(2): pp. 199210.

[11] Iyer, R., Electrokinetic Remediation. Particulate Science and Technology, 2001. Vol. 19.(pp. 219-228.
[12] Acar, Y.B., et al., Electrokinetic remediation: Basics and technology status. Journal of Hazardous Materials, 1995. Vol. 40.(2): pp. 117137.

[13] Acar, Y.B. and A.N. Alshawabkeh, Principles of electrokinetic remediation. Environmental Science \& Technology, 1993. Vol. 27.(13): pp. 2638-2647.

[14] Ahmad, K., K.N. Kassim, and M.R. Taha, Electroosmotic flows and electromigrations during electrokinetic processing of tropical residual soil Malaysian Journal of Civil Engineering, 2006. Vol. 18.(2): pp. 74-88.

[15] Mitchell, J.K., Fundamentals of Soil Behaviour. 2nd ed1993, New York: John Wiley \& Sons Inc.

[16] Ou, C.Y., S.C. Chien, and Y.G. Wang, Soil improvement using electroosmotic with the injection of chemical solutions: field tests. Canadian Geotechnical Journal, 200946): pp. 727-733.

[17] Jayasekera, S. and S. Hall, Modification of the properties of salt affected soils using electrochemical treatments. Geotechnical and Geological Engineering, 2007. Vol. 25.(1): pp. 1-10.

Int. J. of GEOMATE, March, 2014, Vol. 6, No. 1 (Sl. No. 11), pp. 817-823.

MS No. 3347 received on Sept 11, 2013 and reviewed under GEOMATE publication policies. Copyright (C) 2014, International Journal of GEOMATE. All rights reserved, including the making of copies unless permission is obtained from the copyright proprietors. Pertinent discussion including authors' closure, if any, will be published in the March. 2015 if the discussion is received by Sept, 2014.

Corresponding Author: Nasim Mosavat 